\title{
Artesanos La Unión y Emilio Delporte. Barrio-jardín y cooperativismo en la primera periferia de Santiago
}

\author{
Artesanos La Unión y Emilio Delporte. \\ Neighborhood-garden and cooperativism in the first \\ periphery of Santiago
}

\section{Resumen}

Autores:

Alicia Campos* aliciacamposg@uchilefau.cl

Ronald Harris** rharris@uc.cl

Daniel González*** daniel.gonzalez@uai.cl

*Universidad de Chile ** Pontificia Universidad Católica de Chile

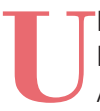

bicadas en las actuales comunas de Independencia y de Providencia, en lo que fuera la primera periferia de la ciudad de Santiago, la Población Artesanos La Unión y la Población Emilio Delporte, construidas en 1926 y 1929 respectivamente, representan iniciativas cooperativistas, en las que podemos reconocer adaptaciones locales de la ciudad jardín. En un contexto de asedio por el cambio de modelo residencial hacia la vivienda colectiva en altura, la valoración de estos conjuntos a través del conocimiento y conceptualización de su morfología, se hace pertinente. En la revisión de la perspectiva histórica del problema de la vivienda para trabajadores en Chile, en que surgen ambos conjuntos y su comparación a la luz de la noción de "barrio-jardín" acuñada por Monserrat Palmer, concluiremos con una reflexión sobre los valores higienistas en las residencias y su vigencia hoy en día.

Palabras clave: barrio-Jardín; cooperativismo; periferia urbana; modelos residenciales.

\section{Abstract:}

Located in the current district of Independencia and Providencia - the first periphery of the city of Santiago - the Artesanos La Unión Village and Emilio Delporte housing complexes, both built in 1926 and 1929 respectively, represent cooperative initiatives in which we can recognize local adaptations of the garden city. In the context of a siege produced by the change of residential model towards a collective high-rise housing, it is pertinent the appreciation of these complexes through its knowledge and conceptualization. In reviewing the historical perspective of the housing problem for workers in Chile, in which emerge both complexes and their comparison in the light of the notion of "gardenneighborhood" coined by Monserrat Palmer, we will conclude with a reflection on the residences' hygienic values and their validity today.

Keywords: garden neighborhood; cooperativism; urban periphery; residential models. 


\section{Introducción}

La reciente valoración de la arquitectura residencial de conjuntos y poblaciones obreras y de trabajadores, ubicadas en lo que fuera una primera periferia de la ciudad de Santiago de Chile, se ha producido, en algunos casos, como lo muestra la Figura 1, por un contraste rotundo entre los modelos residenciales existentes que surgieron durante la primera mitad del siglo XX y el inminente desarrollo inmobiliario privado de vivienda colectiva en altura, acontecido durante las primeras décadas del siglo XXI (Cattaneo, 2011; López, Gasic y Meza, 2012; Valencia, 2017), al amparo de nuevos planes reguladores, o vacíos de los antiguos, que han permitido su aparición (Vergara, 2017).

El impacto de estos inmensos complejos, que en algunos sectores introducen a la rutina de los barrios quinientas nuevas familias, en predios donde anteriormente habitaban cuatro o cinco, ha conducido a las comunidades que habitan los sectores afectados a relevar las características arquitectónicas y urbanísticas de los conjuntos construidos en la primera mitad del siglo XX y a desarrollar iniciativas para su protección. ${ }^{1}$

Estas acciones, han contribuido a la apreciación de diversos grupos de residencias construidas por mutuales, cooperativas, cajas de empleados, en ese periodo. Se trata de viviendas de uno o dos pisos aisladas en el predio, o pareadas por un medianero, con patios y antejardines, que durante largo tiempo permanecieron en la cotidianidad de sus respectivos barrios, evidenciándose recientemente su calidad de habitabilidad (Figueroa et al., 2018), en contraste con los departamentos ofertados por las inmobiliarias en el modelo residencial de vivienda colectiva en altura. Comparativamente, las antiguas viviendas de conjuntos para trabajadores, conformados por unidades de aproximadamente $70 \mathrm{~m}^{2}$ en uno o dos pisos, en predios de 120 a $150 \mathrm{~m}^{2}$, que en su época se consideraban económicas, actualmente solo en la relación de la superficie, presentan una mejor distribución del espacio para la realización de las actividades domésticas, que los departamentos contemporáneos de $38042 \mathrm{~m}^{2}$ de los edificios en altura. Igualmente, los equipamientos de áreas comunes de parques, plazas y la misma

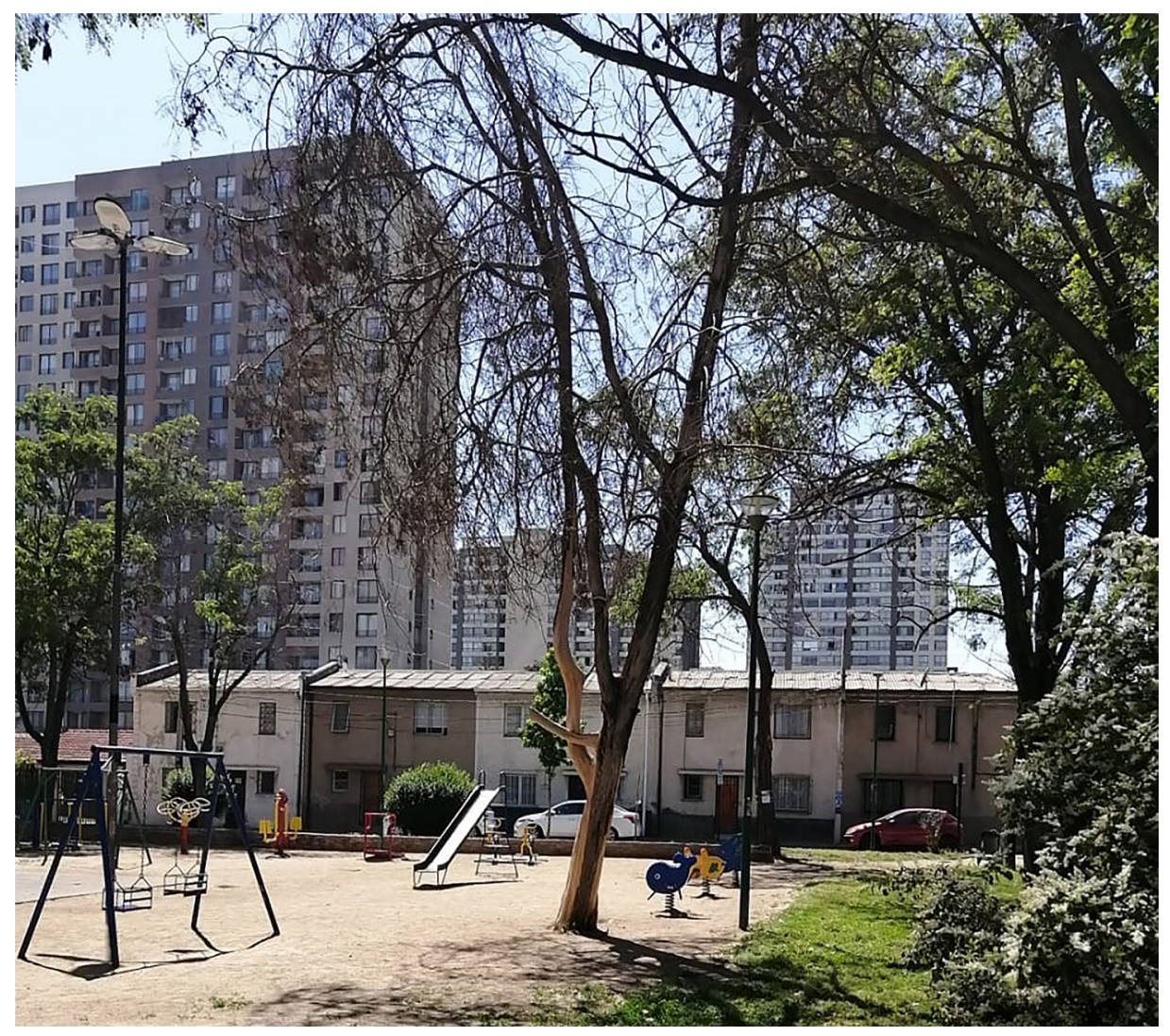

Figura 1: Vista del contraste en los modelos residenciales de la comuna de Independencia de Santiago, Chile Fuente: A. Campos (2020)

${ }^{1}$ Ejemplo de ello es la declarada Zona Típica de Plaza Chacabuco en la comuna de Independencia durante el 2018, que abarca cerca de 30 hectáreas, cuya iniciativa de protección se detonó como una medida para interrumpir la proliferación de las viviendas colectivas en altura y su impacto en las zonas aledañas de baja altura. 
disposición de las viviendas aisladas o parcialmente aisladas en los predios, que incluyen antejardines $y$ platabandas arboladas- construidas como complemento de los conjuntos residenciales del siglo XX aquí referidosotorgan cierta calidad ambiental, conformando entornos urbanos unitarios y armónicos, a diferencia del modelo de vivienda colectiva en altura que, determinado por criterios de optimización de la superficie y densidad establece una relación estrictamente normativa con las áreas verdes, la calle y sus inmediaciones (Vergara y Asenjo, 2019), desestimando el potencial aporte a la calidad urbana de su diseño.

El artículo aquí presentado es resultado de dos investigaciones conducentes al conocimiento y valoración de la arquitectura de poblaciones, conjuntos residenciales de obreros y trabajadores, ubicados en el actual peri-centro de la ciudad de Santiago, en lo que durante las primeras décadas del siglo XX fue considerado periferia de la ciudad. Ambas investigaciones fueron realizadas con financiamiento de los Fondos de Cultura del Consejo Nacional de las Culturas, las Artes y el Patrimonio del Gobierno de Chile, durante los años 2016 y 2018. N 73542 y N 449851 respectivamente

El objetivo es reconocer las características morfológicas comunes en los conjuntos residenciales la Población Artesanos La Unión y Emilio Delporte, de las comunas de Independencia y Providencia respectivamente, que reflejan la apropiación de la ciudad jardín en tanto "barrio-jardín", como producto de la gestión residencial de las cooperativas, en el contexto histórico del primer tercio del siglo XX.

\section{Métodos}

La metodología propone una revisión históricoarquitectónica de la producción de la vivienda obrera que aparece en Chile a principios del siglo XX mediante la ley 1838 de 1906 y la proliferación del modelo de cité a través de la inversión privada, en contraposición a la aparición a las iniciativas de inversión colectiva para la construcción residencial, dadas en el cooperativismo a partir del Decreto Ley $N^{\circ} 308$ de 1925, que se vincula a las primeras experiencias de "barrio-jardín".

En el estudio de la vivienda obrera en Chile, se distinguen las investigaciones de Hidalgo $(2000,2002)$ referidos a la relación entre la gestión y producción residencial, abordando el cooperativismo (2002) y el tipo residencial de ciudad jardín, aunque sin examinar específicamente las determinantes morfológicas y arquitectónicas de este modelo. Por su parte, Monserrat Palmer, en 1984, a través del estudio de algunos conjuntos residenciales en la comuna de Providencia, ha identificado características físicas, espaciales y sociales que introdujeron el modelo residencial aislado en el predio, desplazando el de continuidad de medianerías, utilizando el concepto de "barrio-jardín"

En su documento "La comuna de Providencia y la ciudad jardín" (1984), la autora ha explicado el origen e

\footnotetext{
2 El cité es un conjunto de viviendas de fachada continua que enfrentan un espacio común, privado, el cual tiene relación con la vía pública a través de uno o más accesos (Ortega, 1985).
}

introducción de este modelo en Chile, específicamente en la ciudad de Santiago y la comuna de Providencia, que recibe la influencia de las villas, cottages o chalets europeos, de amplias dimensiones, tanto en los predios como en sus calles arboladas con antejardines, realizadas por arquitectos chilenos y extranjeros, que mediante el conocimiento de revistas internacionales y sus propias experiencias de viaje, comprendieron el modelo mencionado, aplicándolo en algunos de los sectores de la ciudad en crecimiento.

Palmer considera diferencias en la apropiación del modelo de ciudad jardín en distintas áreas de Santiago. Por una parte, el "barrio-jardín", una tipología desarrollada en los alrededores de Santiago a partir de la década del 20. Se trata de poblaciones de viviendas destinadas a trabajadores de servicios públicos o privados, localizadas en la periferia exterior de lo que fuera el ferrocarril de circunvalación (oriente), compuestas por predios de menores dimensiones, que en su conjunto conforman una unidad articulada con calles y plazas según las características expuestas en la Tabla 1. Asimismo, acuña el concepto de "suburbio-jardín", observando que hacia el nororiente de la ciudad, en los sectores de los grupos económicos alto y medio-alto, la idea de ciudad jardín se aplicó a partir de la segunda mitad del siglo $X X$, configurando sitios de mayor superficie y calles más amplias con áreas verdes y un volumen vegetal, que en su conjunto evocaba la sensación de continuidad e intimidad en medio de un entorno verde y asoleado, conformando un paisaje natural envolvente.

La autora nos entrega una interpretación de los principios de la ciudad jardín en los conjuntos y sectores considerados de clase media, enfocada principalmente en determinantes formales y estético-paisajísticos, bajo la premisa de que estos fueron el resultante de una gestión privada (1984, pp. 92-93). Esta idea reviste ciertos matices que aquí se discuten, en tanto limita la comprensión de la ciudad jardín en su respuesta a los requerimientos de higienización de la vivienda y el mejoramiento de la calidad de vida de distintos sectores económicos; asimismo, como un ideal gubernamental que es asimilado también por los segmentos menos favorecidos, quienes se organizaron para su propio beneficio en la búsqueda de mejores soluciones habitacionales.

Indagando sobre las referencias foráneas de la ciudad jardín y su prolífico desarrollo en la densificación del peri-centro de Santiago durante varias décadas del siglo XX, particularmente en Providencia, Palmer identifica al receptor de esta otrora nueva forma de concebir el espacio doméstico -la casa aislada en el predio- en una determinante social, específicamente como la clase media, trabajadores de instituciones afiliados a asociaciones, principalmente privadas.

Más allá de concordar con los descriptores espaciales y arquitectónicos del "barrio-jardín" como una forma de apropiación del modelo exógeno de la ciudad jardín que se aplicó, con sus propios matices, en varias ciudades sudamericanas (Bruno, 2003; Winfield y Marti, 2013), la tesis del presente artículo plantea que un factor determinante en la discusión es el sentido de la gestión y producción residencial, que a partir del accionar 


\begin{tabular}{|l|l|}
\hline \multicolumn{1}{|c|}{ DESCRIPTORES DEL BARRIO-JARDIN } \\
\hline 1 & $\begin{array}{l}\text { Una operación inmobiliaria que configura un conjunto de casas en torno a más de una } \\
\text { calle, que rompe la reticula de la ciudad tradicional y asume unidad en su trazado } \\
\text { oblicuo o sinuoso. }\end{array}$ \\
\hline 2 & Sitios entre 300 y $100 \mathrm{~m} 2$,con casas aislada o pareadas rodeadas de jardin. \\
\hline 3 & $\begin{array}{l}\text { La parcial desmaterialización del limite que define la fachada continua, desplazando el } \\
\text { paramento vertical del limite predial hacia el interior del terreno. }\end{array}$ \\
\hline 4 & $\begin{array}{l}\text { Cierta continuidad entre los elementos que conforman el limite con la calle y la fachada } \\
\text { del volumen. }\end{array}$ \\
\hline 5 & $\begin{array}{l}\text { Relación interior-exterior que se invierte comparativamente con el modelo de vivienda de } \\
\text { fachada continua, volcando al exterior, en los jardines arbolados, una sensación de } \\
\text { intimidad que en la vivienda convencional estaba dada por los patios contenidos. }\end{array}$ \\
\hline
\end{tabular}

Tabla 1: Descriptores del "barrio-jardín" a partir de las consideraciones de Palmer (1984)

Fuente: A. Campos (2020)

cooperativista posibilitó la adquisición de las viviendas para los asociados, asumiendo tempranamente, en la década del 20, la dimensión higienista del modelo ciudad jardín, a menor escala, como un beneficio para la vida familiar y de las comunidades, lo que fue aprovechado por la capacidad organizativa de los grupos de trabajadores, artesanos y obreros, de manera transversal a su "lugar social" o "clase", configurando nuevas porciones urbanas en la otrora periferia de Santiago.

La búsqueda de condiciones dignas de habitabilidad en la vivienda obrera, es un factor que tradicionalmente se ha omitido en la comprensión de la implantación de la ciudad jardín en Chile, quedando asociada a sectores y comunas vinculadas a las clases más acomodadas o clase media- Providencia, San Miguel, Ñuñoa y posteriormente en Las Condes- a través de sus derivaciones modélicas. Es por ello que, como parte de la metodología, el artículo revisa la configuración que el Estado en Chile exploró para la vivienda obrera mediante ciertos principios de la ciudad jardín coincidentes con la idea de "barriojardín", a través de iniciativas previas a la promulgación del Decreto Ley $N^{\circ} 308$, que constituyen antecedentes relevantes de la voluntad por asumir las virtudes de este modelo tempranamente.

La comprobación del supuesto aquí planteado, que releva la acción de las cooperativas en una apropiación de la ciudad jardín contribuyendo a la conformación de una primera periferia de Santiago, se desarrolla mediante una comparación entre dos conjuntos residenciales en la perspectiva del "barrio-jardín" construidos a partir del Decreto Ley N³08 de 1925. Se identifican en ellos los descriptores cuantitativos y cualitativos del "barriojardín" expuestos en la Tabla 1. Se trata de la sociedad de trabajadores artesanos más antigua de Chile, la Sociedad Artesanos La Unión, creada en 1862, que construyó la primera población obrera -homónima- en la actual comuna de Independencia, en lo que fuera la periferia norte de Santiago, con una connotación socia identificada con el sector obrero. El segundo conjunto residencial es la población Emilio Delporte, iniciativa de una cooperativa de empleados vinculados a una empresa privada, cuyas viviendas fueron construidas en la otrora periferia oriente de Santiago, actual comuna de Providencia, que históricamente ha estado identificada con los sectores económicos medios y medios altos.

En la discusión de resultados y conclusiones se reflexiona sobre los elementos comunes que matizan el concepto de "barrio-jardín", su permanencia a través del tiempo, el estado actual y proyecciones de los conjuntos estudiados, así como la potencial aplicabilidad del instrumento comparativo en otros sectores de la misma periferia norte, en vista a consolidar la idea de "barrio-jardín" como una tipología reconocible que ha configurado la ciudad más allá del sector oriente de Santiago.

\section{Resultados}

\subsection{La ley 1838 de 1906, la vivienda obrera, el conventillo y el modelo cité}

El proceso de industrialización, a partir de la segunda mitad del siglo XIX, en Chile, ha sido consignado como un factor relevante para el desarrollo de servicios y de una producción de objetos de consumo, no solo de origen semi-industrial sino también de manufacturas, con la consiguiente incorporación del sector de artesanos y del proletariado fabril en las ciudades (Gross, 1991; Illanes, 2003). En Santiago, el crecimiento urbano implicó una expectativa de oportunidades, de empleos informales, y una demanda residencial por parte de obreros y trabajadores no prevista, que devino en respuestas habitacionales precarias y en la proliferación del hacinamiento en cuartos redondos, ranchos $y$ conventillos desregulados legalmente, dispuestos en condiciones sanitarias deficientes (Hidalgo, 2000). Sumado a ello, las consecuencias de las enfermedades infecciosas que afectaron al país durante el periodo, suscitaron el desarrollo de acciones y políticas en materia de higiene y salud pública (Ibarra, 2016), que convocaron el mejoramiento de las condiciones habitacionales para los grupos sociales menos favorecidos. La respuesta 
se manifestó desde el ámbito privado, generándose alternativas incipientes bajo el espíritu de la filantropía (Población León XIII, 1891) y mediante la iniciativa empresarial que construyó viviendas, principalmente para renta. Aunque la Ley de Habitaciones Obreras de 1906 exigía las mejoras para las condiciones mínimas de habitabilidad y contribuía económicamente a su implementación, una de las razones de su derogación fue la desviación de su cometido esencial, que había devenido en favor de la especulación en el precio de arrendamiento de las viviendas mejoradas y posteriores conflictos, por el alza del valor de renta de los recintos o inmuebles que cumplían la norma, producto de lo cual se creó el Decreto Ley de arrendamiento de 1925, considerada la primera acción del Estado para el control de los alquileres y mediación de conflictos entre propietarios e inquilinos (Hidalgo, 2002).

Si bien la Ley de habitación obrera de 1906 y su ordenanza establecían requisitos específicos para la condición higiénica de las viviendas, como por ejemplo la presencia de alcantarillado, agua potable, ingreso de luz natural y ventilación en los recintos, no se refería a las relaciones de la ocupación de suelo en los predios, lo que quedaba suscrito potencialmente a las ordenanzas de aplicación, por ejemplo, municipales. Este aspecto es fundamental al considerar que la capacidad ejecutiva en la construcción de viviendas estuvo concentrada principalmente en los empresarios, quienes optimizaban la rentabilidad de sus inversiones, lo que se vio reflejado en el aprovechamiento de la superficie disponible para la edificación de unidades para venta o renta, y en la elección de predios localizados en la periferia de la ciudad:

Pese a sus buenos propósitos, durante los veinte años de vigencia de esta Ley (1906-1925) el Estado no pudo levantar más de dos poblaciones con un total de 396 casas. Por su parte, la iniciativa privada, acogiéndose a los beneficios y garantías tributarias que dicha ley impuso, construyó otras 3.246 viviendas durante el mismo lapso, en especial conventillos y "cités" en diversas poblaciones creadas en la ciudad (De Ramón, 1990, p. 10).

En este sentido, la mayoría de los conjuntos construidos durante la vigencia de la Ley, siguió un esquema de ocupación predial con fachada continua tipo cité, con un largo recorrido general central, que posibilitaba el acceso a las unidades residenciales, quedando estas distribuidas de manera adosada a los medianeros longitudinales como fondo de las viviendas, optimizando las posibilidades de utilización del predio. Si bien la urbanización de los lotes a partir de la Ley 1.838 exigió un aumento de las condiciones de habitabilidad, estas se concentraron en los servicios y no en la morfología de las viviendas y su relación con el predio, por lo que la mayor parte de los conjuntos prosiguió con la distribución de ocupación en continuidad, como lo muestra la Figura 3, conformando bloques y manzanas llenas.

\subsection{Cooperativismo y barrio-jardín}

La Ley 1.838 de Habitación Obrera se mantuvo en vigencia hasta 1925, fecha en que comenzó a regir el Decreto Ley N 308, llamado "Fomento de Habitación Barata". El principal motivo de la modificación del marco legislativo fue la ineficiencia del instrumento legal de 1906, para solucionar el problema de la habitación popular (De Ramón, 1990). Según lo planteado por Hidalgo a partir del Decreto Ley $N^{\circ} 308$ :

\begin{abstract}
Las cooperativas de vivienda tuvieron una importancia significativa en la Ley de 1925; a ellas se les dio preferencia en los préstamos que otorgaban las instituciones financieras definidas en esa legislación (...) Las cooperativas de vivienda son puestas por primera vez en una posición importante para resolver el déficit de residencias. El aporte a realizar por las sociedades de empleados y trabajadores para solucionar su respectiva falta de habitaciones fue considerado como uno de los puntos fundamentales de la ley. En la ciudad de Santiago, y al amparo de esta legislación, se formaron 19 cooperativas de edificación (Hidalgo, 2002, p. 90)
\end{abstract}

Entre las cooperativas mencionadas se contabilizan la Cooperativa de Edificación y Consumos Alimenticios La Unión Ltda., gestora de las poblaciones Artesanos la Unión y Dávila Baeza, además de la Cooperativa de Empleados Emilio Delporte, responsable de la población homónima aquí tratada.

Asimismo, el autor señala que la tipología residencial utilizada por las cooperativas fue la vivienda unifamiliar, inspirada en el modelo de la ciudad jardín. Estas incluían, además de la vivienda de fachada continua adosada

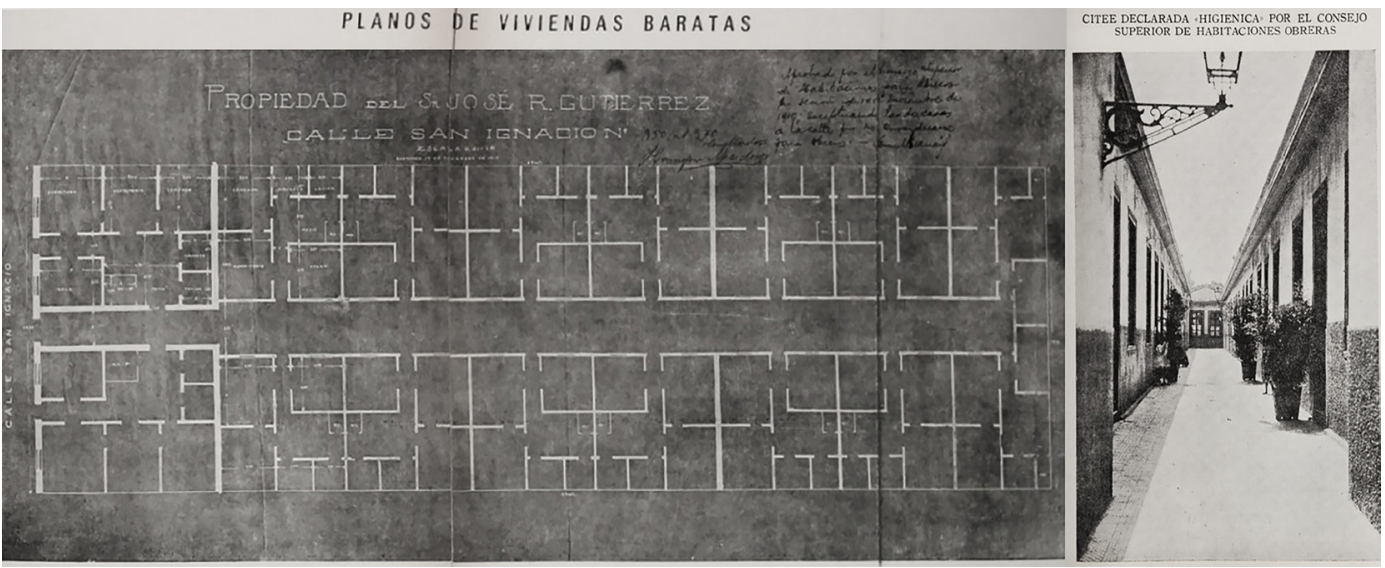

Figura 2: Plano y fotografía del Cité considerado como vivienda higiénica por el Consejo de Habitaciones. Se aprecia la morfología de unidades continuas adosadas con un corredor central

Fuente: Revista de la Habitación (1921) 
a los medianeros, unidades aisladas o semi-aisladas en los predios, con patios posteriores, antejardines y platabandas que integraban vegetación $y$, en algunos casos, incluso plazoletas que articulaban las áreas arboladas:

La casa unifamiliar en los límites de la ciudad, con predios amplios y con todas las condiciones favorables de la higiene moderna, empezó a ser vista como uno de los objetivos residenciales de los sectores medios y medios bajos (Hidalgo, 2002, p. 101).

Sin duda, la participación de las cooperativas enfocadas en la adquisición de los inmuebles (y no en la renta) para conferir a sus afiliados la calidad de propietarios en conjuntos residenciales o poblaciones, incentivó las exigencias en las construcciones, introduciendo mejores parámetros de calidad de los inmuebles. La condición de vivienda unifamiliar, la separación del bloque continuo y la localización aislada del predio, la presencia de árboles y plazas, más allá de los aportes estéticos a los conjuntos, fueron aspectos morfológicos que contribuyeron a la iluminación y ventilación de las viviendas, así como a la presencia de patios exteriores privados para el desarrollo de variadas actividades, diversificando el programa habitacional. Asimismo, cabe señalar que el enfoque en el aprovechamiento de los recursos en el cooperativismo es el de un modelo comunitario:

Las cooperativas nacen como una asociación voluntaria de personas, que se unen para trabajar con el fin de lograr beneficios para todos sus integrantes y para la comunidad en la que viven (Ministerio de Economía, Fomento y Turismo, 2014 p. 5).

Esta idea coincide con la configuración morfológica de ciudad jardín, o más específicamente "barrio-jardín", en la que todas las unidades configuran una totalidad integrada, dada por las características formales pero también por la presencia de espacios comunes integrados que proyectan el sentido del cooperativismo al uso de espacio

En Chile, el movimiento cooperativista, como asociación de trabajadores para el socorro mutuo y la educación, encuentra sus orígenes a partir de 1875, (Carrillo y Jara, 2010; Del Campo y Radrigán, 1998), articulándose a nive latinoamericano con la creación de la Alianza Cooperativa Internacional, en 1895 (Mora, 2012). A nivel nacional, la primera Ley de Sociedades Cooperativas $N^{\circ} 4.058$, fue promulgada en 1924, indicando los fines de asociación, entre los que se mencionaba el construir casas para venderlas o arrendarlas a sus asociados (Art. $2 \mathrm{~N}^{\circ} 3$ ). Las cooperativas se debían constituir con un número no inferior a 20 integrantes y sus estatutos podían ser aprobados con dos tercios de la totalidad de los socios quienes, para pertenecer a una Cooperativa, debían no tener fines de lucro, pudiendo ser dueño de un máximo del $10 \%$ del capital de la Sociedad. La ley planteaba que las Sociedades Cooperativas se administraban mediante una Junta General de Socios, un Consejo de Administración o Directorio y una Junta de Vigilancia. Los estatutos de cada Cooperativa, aprobados por sus socios, determinaban las condiciones para la formación del Directorio y elección de un Director, sus atribuciones y las formas de ejercerlas. Asimismo, determinaba la conformación de la Junta de Vigilancia. A través de estos instrumentos, se intuye la incidencia de los socios en la toma de decisiones de las Sociedades Cooperativas y de sus potenciales inversiones, otorgando más posibilidades en el caso de la proyección de viviendas, para la elección en las configuraciones espaciales y la superación de esquema de cités o de pasajes con viviendas adosadas, como lo muestra la Figura 2

En cuanto a las facilidades para las inversiones, el funcionamiento de las Sociedades Cooperativas contó con exención y rebajas de contribuciones e impuestos y montos para préstamos devenidos de la Ley de Presupuestos. Por otra parte, el Decreto Ley $\mathrm{N}^{\circ} 308$ otorgó preferencia para extender préstamos a las Cajas de Ahorro, Sociedades de Obreros y de Empleados con personalidad jurídica, Cooperativas de empleados públicos, privados, de instituciones de defensa, empresas del Estado, para construir habitaciones destinadas a ser trasferidas a sus socios y ulteriormente a los particulares que edificarían para el arrendamiento.

Aunque el Decreto Ley 308 establecía que el tipo de construcción preferente a financiar sería el edificio cooperativo-colectivo, como un cuerpo destinado a diez familias co-propietarias del inmueble, según lo ya referido por Hidalgo:

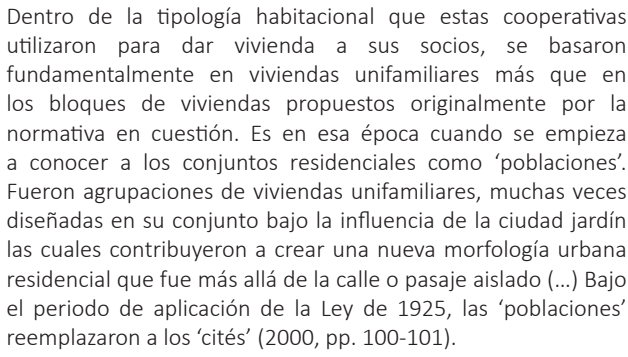

Si bien esta reflexión se centra en la relación entre configuración urbana (crecimiento en una primera periferia de Santiago) con el influjo de la ciudad jardín, el autor solo menciona informativamente sobre esta tipología como un modelo utilizado por las cooperativas. Las apropiaciones de esta forma de ocupación de los predios, en diversos contextos urbanos, han adquirido diversos matices; por nuestra parte, aquí hacemos énfasis en la incidencia del cooperativismo a través de Decreto-Ley $N^{\circ} 308$, para la aplicación inicial y posterior desarrollo del otrora nuevo modelo devenido de la ciudad jardín, siendo un factor relevante para la gestión de la vivienda obrera y de trabajadores, que encontró sentido en la forma de agrupación de las viviendas aisladas en el predio, configurando conjuntos unitarios y reconocibles, con sus propias características urbanas.

\subsection{Antecedentes de la ciudad jardín en la gestión estatal}

El conocimiento de la gestión de las cooperativas obreras para la generación de viviendas de sus afiliados a nivel internacional (Frías, 1911; Casanueva, 1913; Correa, 1924) y los beneficios en las consideraciones higienistas asociados al modelo ciudad jardín, venían siendo difundidos en Chile ya desde las primeras décadas del siglo XX por diversos estudios institucionales y publicaciones (Larraín Bravo, 1909; Subercaseaux, 1920) que aportaron una mirada crítica a la acción 
estatal, asumiendo los aportes del modelo de vivienda aislado en el predio. El Consejo Superior de Habitaciones Obreras, institución creada a partir de la Ley $N^{\circ} 1.838$, participaba de congresos a nivel internacional cuyas temáticas se centraban en la vivienda barata, teniendo conocimiento de la experiencia inglesa, francesa, belga, cubana y argentina, informando además a través de su publicación, Revista de la Habitación, de lo acontecido en varios otros países.

En el primer número del año 1921 se difunden los beneficios que el cambio de modelo residencial aportaría a la calidad de vida de los trabajadores (Subercaseaux 1920). En el $N^{\circ} 12$ de la primera versión de la Revista de la Habitación, el Consejo Superior de Habitaciones Obreras (1921) presentó un ensayo de solución residencial, construido a manera de piloto por la misma institución, en avenida San Luis 1590, de la actual comuna de Independencia; la llamada Casa de Yeso, que se muestra en la Figura 3, que utilizó este material en revestimientos y tabiques interiores, asumiendo cierta optimización en el sistema constructivo y además una ocupación del predio semi-aislado con patio y jardines anteriores y posteriores.

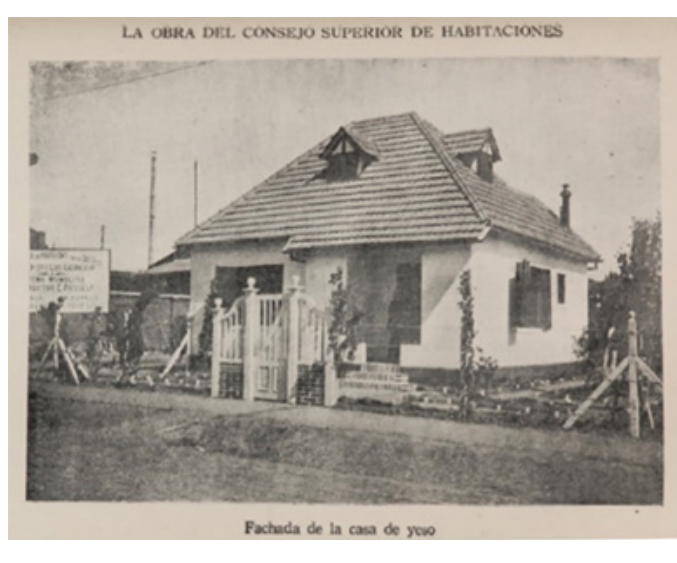

Figura 3: Vista de la Casa de Yeso, prototipo de vivienda higiénica construida en calle San Luis, Independencia Fuente: Revista de la Habitación (1921, p.700)

En la inauguración del prototipo, el Intendente de Santiago señalaba:

Nadie en nuestro país tiene derecho de desinteresarse de lo que se relaciona con la vida de las clases populares porque todos estamos ligados a ellos por vínculos materiales y morales y por los contactos ineludibles de una labor común (...) Fuerza es que nosotros aunemos las voluntades para darle mayor bienestar físico, base del bienestar espiritual. Necesario es que en la grave hora presente el Gobierno y los particulares dirijan una acción común para desarrollar un programa efectivo de renovación de los barrios populares; que se unan todos para hacer más bella, más higiénica, más culta la vivienda obrera (...) Aspiración del Consejo de Habitaciones para Obreros es edificar en este amplio sitio, entre árboles y jardines, pequeñas casas, cual ésta, para manifestar a todos los que se interesan por el problema de la habitación popular, que sus ambiciones pecuniarias no están reñidas con los preceptos de la higiene, ni con los principios de la estética. (Mackenna,1921, p. 704)

Esta iniciativa refleja la apropiación del modelo ciudad jardín, en una escala y dimensiones más reducidas, posibles de interpretar en la idea de "barrio-jardín", vinculada tempranamente a las voluntades públicas por otorgar mejores condiciones en la calidad de vida de los obreros, instalándose un ideal en la forma de vida que las viviendas aisladas aportarían, que posteriormente sería replicado por las asociaciones y cooperativas que a partir del Decreto Ley 308 y de la ley 4.058 tuvieron mayores posibilidades de acceder a formas de adquisición de la casa propia.

En lo que sigue, se revisarán las características que de cierto modo definen el "barrio-jardín" en dos conjuntos residenciales de acuerdo a los descriptores presentados en la Tabla 1. El primero, ubicado en lo que fuera la periferia norte, como lo muestra la Figura 4, en un sector que se identificó durante el siglo XX con la proliferación de barrios obreros y de un artesanado calificado. E segundo, ubicado en la otrora periferia oriente de Santiago, en la comuna de Providencia, según se aprecia en la Figura 7.

Ambos conjuntos gestionados a partir del Decreto Ley $N^{\circ} 308$ de 1925, exponen las iniciativas de agrupaciones de trabajadores que optaron por una modalidad que evoca algunos aspectos de la ciudad jardín, desde una perspectiva coincidente con las voluntades estatales por explorar formas residenciales en vista a una mejora de las condiciones de habitabilidad de los grupos referidos.

\subsection{Población Artesanos La Unión}

Ubicada en la actual comuna de Independencia, entre Av. Einstein, Av. El Guanaco, calle Pantaleón Véliz y la misma Av. Independencia, la Población Artesanos La Unión consta de 195 sitios en 11 manzanas. Se encuentra contigua a la Población Dávila Baeza y en su conjunto, forman un pequeño sector residencial denominado "Población Chacabuco", con un trazado definido en torno a una plazoleta central.

Construida entre 1925 y 1926, el área residencial fue completada en la década del 40, mediante la edificación de un tercer grupo de viviendas que continuó con varios aspectos morfológicos de las iniciales.

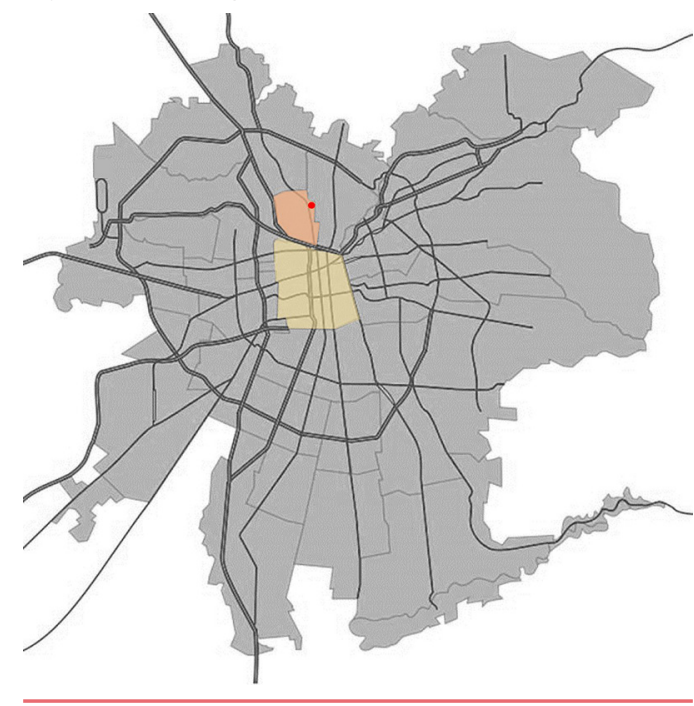

Figura 4: Esquema de ubicación de la Población Artesanos La Unión en la comuna de Independencia al norte de la comuna de Santiago, antigua área urbana de la ciudad Fuente: A. Campos (2020) 
La población Artesanos la Unión recibe su nombre de la Sociedad Artesanos La Unión, entidad creada 1862 por artesanos liderados por Fermín Vivaceta. Llegó a ser una de las instituciones más relevantes del movimiento mutualista y cooperativista en Chile. Se encuentra aún vigente y sus archivos fueron declarados Monumento Histórico en el año 2007. Destinada a la protección y promoción del buen vivir de sus socios, la población Artesanos La Unión es una de las iniciativas precursoras en la materia. Según lo expuesto por el Presidente de la Sociedad, Vicente Villalobos, en 1926 :

Preocupación constante de los Directorios de la S.A.U. ha sido el problema de la habitación higiénica, y, en este sentido, ha sido, también, la primera institución obrera que logró la construcción de una población para sus asociados. Lo que permitió, a la vez, que otras instituciones congéneres lograran alcanzar idénticos fines. Dicha población fue edificada con cargo a la Ley $N^{\circ} 308$ y constituyó una obra de importancia y magnitud para su tiempo (Sociedad Artesanos La Unión, 1962, p. 20).
Mediante la acción de la Cooperativa de Edificación y Consumo Alimenticio La Unión Ltda. se gestionaron las poblaciones Artesanos La Unión y Dávila Baeza (Hidalgo, 2002), y a través de la Caja de Crédito Hipotecario los créditos para adquisición de las unidades.

En el plano de la Figura 5 se aprecia que las viviendas de 70 a $100 \mathrm{~m}^{2}$ se disponen aisladas o pareadas por un medianero, en predios que van desde los 160 a los $200 \mathrm{~m}^{2}$ aproximadamente, conformando manzanas homogéneas en un trazado determinado por calles longitudinales de $6 \mathrm{~m}$ de ancho y veredas de $2 \mathrm{~m}$, que convergen en una plaza central cuya superficie supera los $2000 \mathrm{~m}^{2}$. Si bien las calles permiten el tránsito cómodo en ambos sentidos, las veredas son angostas e incluyen árboles dispuestos regularmente, que contribuyen a la percepción de unidad del conjunto. Por otra parte, el límite de los predios con la vía pública consiste en un muro de baja altura que posibilita la continuidad visual

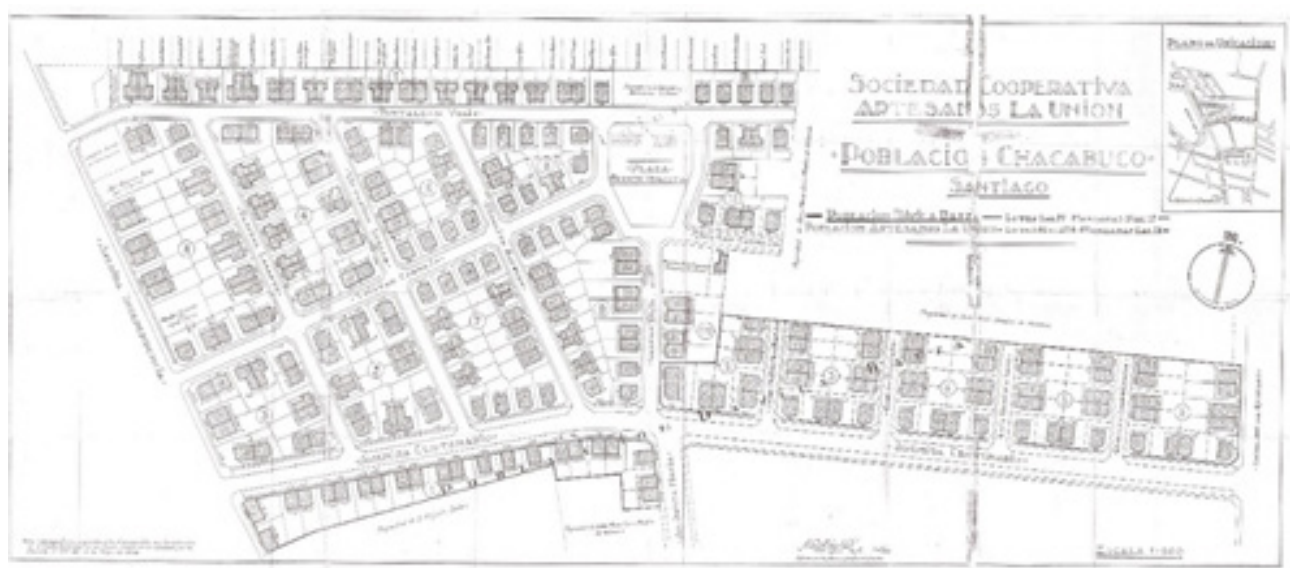

Figura 5: Plano Población Artesanos La Unión y Población Dávila Baeza Fuente: Conservador de Bienes Raíces de Santiago (2016)
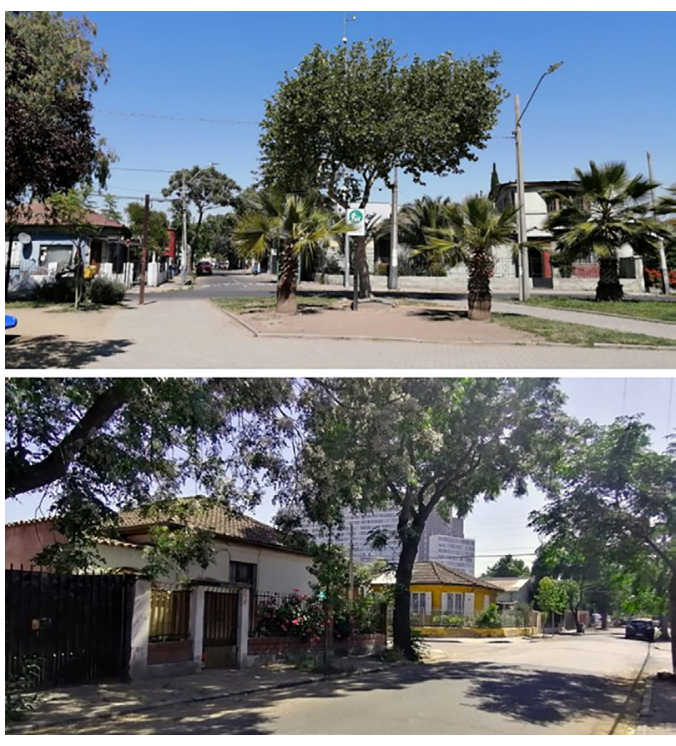

Figura 6: Vistas de las tipologías residenciales originales de la Población Artesanos La Unión y de la Plaza Fermín Vivaceta

Fuente: A. Campos (2020) hacia los antejardines que entregan 2 m entre la línea oficial y la edificada; estos cuentan, en la mayoría de las viviendas, con árboles y arbustos que contribuyen a esta apreciación de continuidad, matizando la privacidad los espacios exteriores y aportando al conjunto en general una escala y atmosfera de intimidad.

\subsection{Población Emilio Delporte}

El conjunto de viviendas ubicadas en calle Emilio Delporte entre Av. Miguel Claro y Av. Manuel Montt, en la comuna de Providencia, en lo que fuera una primera periferia oriente de la ciudad de Santiago, como lo muestra la Figura 7, recibe su nombre de la agrupación de trabajadores de la casa comercial Emilio Delporte organizados en la Cooperativa Arturo Prat.

Esta población es el primer trabajo del arquitecto Luciano Kulczewski vinculado a una cooperativa de viviendas. Construidas en 1929, se trata de 39 unidades que se disponen, originalmente según la planimetría aprobada por los organismos pertinentes, entre las calles ya mencionadas y calle Manuel Antonio Maira, en una urbanización de un predio de mayores dimensiones, que acusa el avance de la ciudad sobre los entornos rurales de la época. 


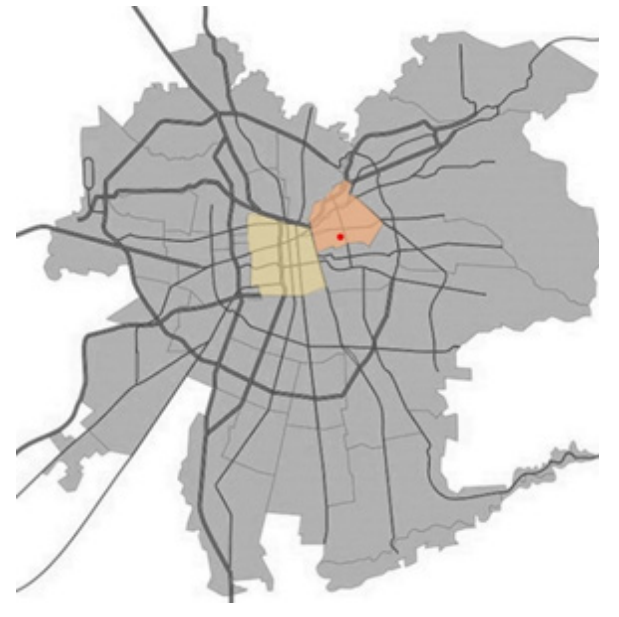

Figura 7: Esquema de ubicación de la Población Emilio Delporte en la comuna de Providencia al oriente de la comuna de Santiago, antigua área urbana de la ciudad Fuente: A. Campos, (2020)

La geometría de los trazados viales y de los predios es ortogonal, en lotes de cerca de $300 \mathrm{~m}^{2}$, las calles de 6 $\mathrm{m}$ permiten el tránsito en dos vías y las veredas, aunque angostas de $2 \mathrm{~m}$, presentan una arbolada de ejemplares dispuestos regularmente, lo que se aprecia en la Figura 8.

Las viviendas de $70 \mathrm{~m}^{2}$ aproximadamente, conforman unidades cuya volumetría presenta antejardines parciales alternados con fachadas continuas que se despliegan en una tipología pareada por un medianero, con excepción de una unidad pareada por ambos.

De manera general se trata de viviendas que, si bien se encuentran semi-aisladas en el predio, presentan su fachada principal en el límite de la línea de edificación, configurando una secuencia de masa y vacíos alternada con vegetación, como lo muestra la Figura 9.

Esta disposición otorga unidad al conjunto que conserva algunos elementos de la ciudad tradicional, como la linealidad y la clara definición material del límite con la calle, pero también incluye la expresión de un follaje que evidencia hacia el exterior la vivencia privada de las zonas de patios, cumpliéndose de esta manera la idea mencionada por Palmer, de un interior que se exterioriza para configurar una unidad con el entorno urbano y arbóreo.

Además, el caso de las unidades residenciales aquí referidas, diseñadas por Luciano Kulczewski, presentan detalles de diseño en sus fachadas que otorgan individualidad a cada unidad, pero también acentúan la idea de exteriorización del interior a través de la continuidad de elementos materiales, como por ejemplo el tratamiento del acceso que configura un espacio intermedio, en la disposición zaguanes con vanos, medios muros o arcos ochavados.

Este recurso, que relativiza la rigidez del límite hacia el espacio público, es utilizado también en las fachadas interiores de las viviendas, generando espacios intermedios que dialogan en una escala doméstica con las distintas posibilidades que el patio presenta, recibiendo iluminación, ventilación y asoleamiento desde sus tres fachadas.

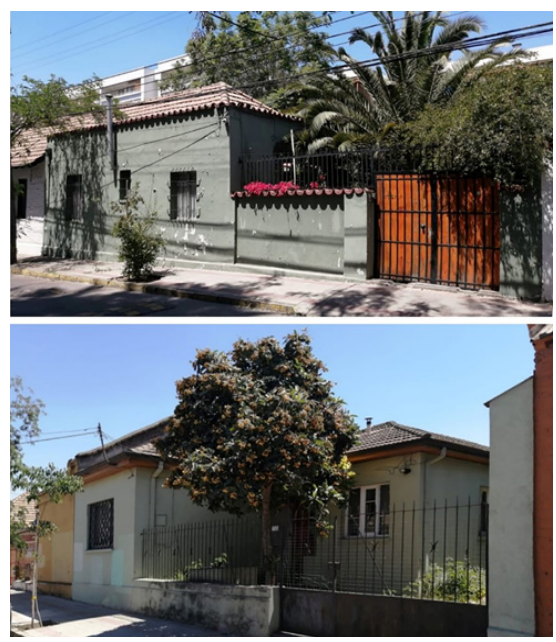

Figura 9: Vistas de las residencias originales de la Población Emilio Delporte

Fuente: A. Campos (2020)

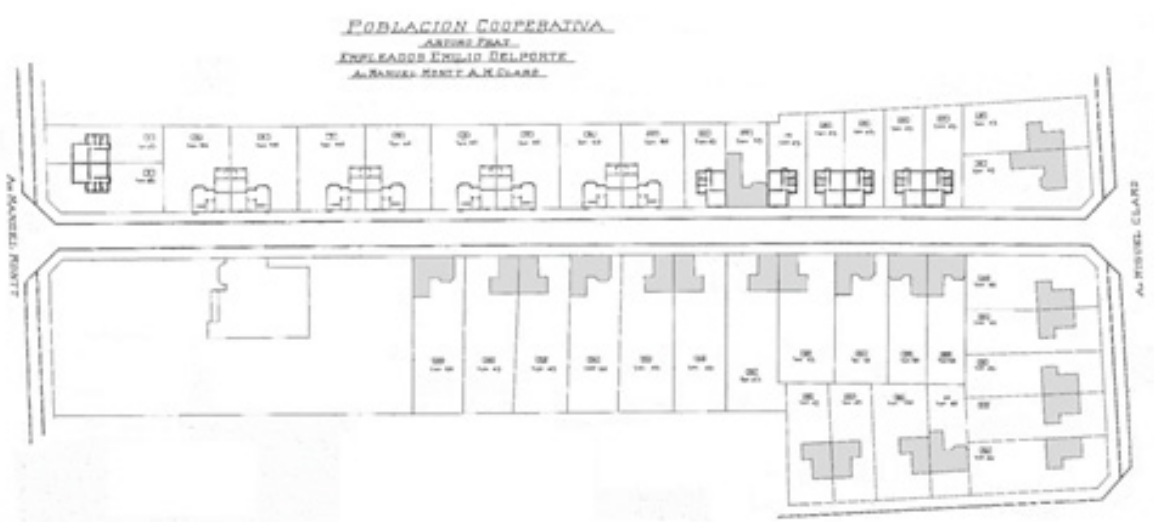

Figura 8: Plano Población Emilio Delporte

Fuente: Conservador de Bienes Raíces de Santiago (2018) intervenidos por los autores 


\section{Discusión y conclusiones}

Ambas poblaciones se localizan en lo que fuera una primera periferia de la ciudad de Santiago, pero en sectores con una identidad muy distinta: el otrora barrio de Independencia, en la Chimba, con una determinante social vinculada a la presencia de órdenes religiosas, impronta sanitaria, productiva y habitación de la mano de obra artesanal y obrera; por otra parte, la comuna de Providencia, con una clara proyección de crecimiento urbano residencial para trabajadores públicos y privados.

Es interesante constatar que la primera población obrera gestionada por la organización mutualista a través de la figura de cooperativas, la Población Artesanos La Unión, realizada en 1926, se inspiró en los beneficios de la ciudad jardín para la calidad del habitar en cuanto a la llamada construcción higiénica que, excediendo su configuración unitaria, es gestionada y diseñada en una consideración colectiva. Esta visión de conjunto se expresa en el trazado de las calles, la plaza, la ubicación de las manzanas y disposición de los predios, pero también en el tratamiento del límite entre lo público y lo privado, que posibilita una continuidad visual hacia el interior de estos, lo que se complementará, con el pasar del tiempo, con la expresión del material vegetal hacia su exterior. E trazado, las dimensiones de los terrenos, la volumetría de las viviendas y su proximidad, la escala total del conjunto, evidencian una interpretación urbana de la ciudad jardín más cercana a la idea de "barrio-jardín", de acuerdo a los descriptores enunciados por Palmer.

En lo concerniente a la Población Emilio Delporte, para trabajadores de la casa comercial homónima, su dimensión, en cuanto al número de casas y superficie general, es menor, -comparativamente con la Población Artesanos la Unión-, extendiéndose principalmente en una calle y parte de su paralela; por lo que la idea de "barrio jardín" queda acotada; asimismo la configuración del límite público-privado conserva elementos de la ciudad tradicional, principalmente en la linealidad de la fachada general del conjunto, conformada por las parcialidades de las fachadas de cada vivienda, que se alternan con los tramos de cierres más permeables, como se muestra en la Figura 9.

Sin embargo, en ambos casos, las unidades residenciales, en su mayoría, se posicionan adosadas por un medianero en el predio, dejando espacio para antejardín, patio posterior y lateral, así como una volumetría que expone dos o tres fachadas dentro del predio, lo que se puede apreciar en la Figura 8. El tratamiento de estas fachadas en las dos poblaciones aquí referidas es muy distinto. Mientras en Artesanos La Unión se contribuye a una definición categórica del volumen, en Emilio Delporte las fachadas presentan un repertorio de elementos arquitectónicos que generan espacios intermedios, complementándose con los patios exteriores de las viviendas, reforzando la idea de intimidad mediante entornos arbolados envolventes. Por lo tanto, si bien en Artesanos La Unión el límite entre lo público y lo privado se hace inmaterial, contribuyendo a la comprensión de conjunto como una totalidad, logrando una escala y ambiente unitario complementado por el material vegetal, en Emilio Delporte las unidades, mucho más diferenciadas entre sí, presentan una vinculación con sus entornos inmediatos donde la arquitectura cobra mayor presencia mediante el diseño de los detalles y calidades espaciales intermedias.

A manera de conclusión, cabe señalar que, como bien lo indicó Vicente Villalobos en 1926, la iniciativa de la población Artesanos La Unión se replicó en las inmediaciones del barrio, bajo la Ley de Cooperativas o bien bajo otros instrumentos para la gestión de las viviendas de obreros, derivando en la aparición de otros segmentos urbanos de similares características que durante la primera mitad del siglo XX contribuyeron al desarrollo de conjuntos que coinciden con la idea de "barrio-jardín", en la actual comuna de Independencia, quedando instalada la morfología de vivienda aislada en el predio en entornos verdes.

El conocimiento de estos inmuebles y su vinculación con los principios de ciudad jardín a través de la idea de "barrio-jardín" contribuyen a la valoración de sectores peri-centrales en permanente asedio inmobiliario, y sin duda constituyen experiencias que, dada la densificación de los centros y peri-centros urbanos, deben ser consideradas en atención a cautelar la diversidad de los ambientes y escalas de la ciudad, la representatividad de distintos sujetos sociales a lo largo de la historia de las ciudades y por último, en atención a procesos comunes en ciudades a nivel latinoamericano. En este sentido, la idea de "barrio-jardín" viene a aportar actualmente un sentido de identidad que invita a la participación de los habitantes en la conservación de los entornos verdes cada vez más escasos.

Una de las amenazas más evidentes de los conjuntos residenciales es la alteración en la morfología de las unidades, siendo una de las dificultades más recurrentes en la investigación el reconocimiento de las viviendas originales, que, dado el paso del tiempo, puedan pervivir con modificaciones menores. En este sentido, y de manera general, aunque las ampliaciones de las viviendas son consideradas en los planes reguladores comunales con un crecimiento de hasta en dos pisos, esta variación no altera sustancialmente la escala y las variables cualitativas del "barrio-jardín" en los conjuntos arquitectónicos aquí tratados, siendo mucho más invasivo el crecimiento inmobiliario de las inmediaciones, como se observa en las Figuras 6 y 9, para la conservación de su espacialidad.

Actualmente, a casi cien años desde la creación de ambas poblaciones, se puede afirmar que estas han mantenido su función residencial, lo que ha contribuido a su conservación, presentando atributos para ser valorados formalmente en vista a conformar las llamadas Zonas Típicas, instrumento que en la legislación chilena reconoce y protege los bienes inmuebles urbanos o rurales que conforman unidades de asentamiento representativo de la evolución de la comunidad. 
Cómo citar este artículo/How to cite this article: Campos, A., Harri s, R. y González, D. (2021). Artesanos la unión y Emilio Delporte. Barrio-jardín y cooperativismo en la primera periferia de Santiago. Estoa. Revista de la Facultad de Arquitectura y Urbanismo de la Universidad de Cuenca, 10(20), 129- 140. doi: https://10.18537/est.v010.n020.a11

\section{Referencias bibliográficas}

Bruno, P. (2003). Reflexiones para una historia conjunta: derivaciones americanas de la ciudad jardín en la extensión y planificación moderna de ciudades de Argentina y Brasil, 1930-1945. Registros. Revista de Investigación Histórica, (1), 69-84. https://revistasfaud. mdp.edu.ar/registros/article/view/381

Carrillo, M. y Jara, P. (2010). Acercamiento a los cambios en la vida interna y externa de las sociedades mutualistas en Chile desde 1930-1963. Historia Actual Online, (23), 51-64. https://historia actual.org/Publicaciones/index. php/hao/article/view/497

Casanueva, L. (1913) Apuntes sobre el problema de habitaciones obreras en Chile. Pacífico Magazine, 18 (8), 252-266.

Cattaneo, R. (2011). Los fondos de inversión inmobiliaria y la producción privada de vivienda en Santiago de Chile: ¿Un nuevo paso hacia la financiarización de la ciudad? EURE, 37(112), 5-22. https://dx.doi.org/10.4067/S025071612011000300001

Correa A. (1924). Habitaciones para obreros: estudio y conclusiones presentados al Congreso Internacional de Economía Social de Buenos Aires. Imprenta y Lit. La Ilustración.

Del Campo, P. y Radrigán Rubio, M. (1998) Trayectoria y proyecciones del Cooperativismo en Chile. CIRIEC-España Revista de Economía Pública, Social y Cooperativa, (30), 147-158.

De Ramón, A. (1990). La población informal. Poblamiento de la periferia de Santiago de Chile. 1920-1970. EURE, 16(50), 5-17. https://www.eure.cl/index.php/eure/ article/view/1049

Frías, E. (1911). Las habitaciones obreras en Chile y en el Extranjero. Oficina del Trabajo. Imprenta Santiago.

Figueroa, D., Campos, A., Duarte, P. y Cares, M. (2018). Arquitectura Patrimonial de Independencia. Una mirada histórica y urbana desde el siglo XXI. Ocho Libros.

Gross, P. (1991). Santiago de Chile (1925-1990). Planificación Urbana y Modelos Políticos. EURE. 17 (5253), pp. 27-52. https://www.eure.cl/index.php/eure/ article/view/1073
Hidalgo, R. (2000). El papel de las leyes de fomento de la edificación obrera y la Caja de la Habitación en la política de vivienda social en Chile, 1931-1952. INVI, 15(39), 92-120. http://200.89.73.130/index.php/INVI/article/ view/257/232

Hidalgo, R. (2002). Vivienda social y espacio urbano en Santiago de Chile: Una mirada retrospectiva a la acción del Estado en las primeras décadas del Siglo XX. EURE, 28(83), 83-106. https://dx.doi.org/10.4067/S025071612002008300006

Ibarra, M. (2016). Higiene y salud urbana en la mirada de médicos, arquitectos y urbanistas durante la primera mitad del Siglo XX en Chile. Revista médica de Chile, 144(1), 116-123. https://dx.doi.org/10.4067/S003498872016000100015

Illanes, M.A., (2003) La revolución solidaria Las Sociedades de Socorros Mutuos de Artesanos y Obreros: un proyecto popular democrático, 1840-1887. Polis (5), https://journals.openedition.org/polis/6954

Larraín R. (1909). La higiene aplicada en las construcciones: (alcantarillado, agua potable, saneamiento, calefacción, ventilación, etc.). Cervantes.

López, E., Gasic I. y Meza, D. (2012). Urbanismo proempresarial en Chile: políticas y planificación de la producción residencial en altura en el peri-centro del Gran Santiago. INVI, 27 (76), 75-114. https://revistainvi. uchile.cl/index.php/INVI/article/view/62511

Mackenna, A. (1921) Inauguración de la Casa de Yeso para obreros. Revista de la Habitación, 12 (1), 701-709.

Mora, A. (2012). Visión histórica del movimiento cooperativo en América Latina. En Mogrovejo, R., Mora, A. y Vanhuynegem, P. (Eds). El Cooperativismo en América Latina (pp. 29-86). La Paz. Organización Internacional de Trabajo para los Países Andinos.

Ministerio de Economía, Fomento y Turismo. Gobierno de Chile (2014). El Cooperativismo en Chile. División de Política Comercial e Industrial. Gobierno de Chile. https:// www.economia.gob.cl/wp-content/uploads/2014/07/ElCooperativismo-en-Chile.pdf

Ortega, O. (1985). El Cité en el origen de la vivienda chilena. Ciudad y Arquitectura, (41).

Palmer, M. (1984). La comuna de Providencia y la ciudad jardín. EURE, 11 (31), 75-96. https://www.eure.cl/index. php/eure/article/view/944/55

Sociedad Artesanos La Unión (1962). Primera Población Obrera en Chile. En Primer Centenario de la Sociedad Artesanos La Unión. Imp. Stanley.

Valencia, M. (2017). Tensiones entre procesos de patrimonialización y modernización neoliberal. El caso de los paisajes culturales modernos: conjuntos habitacionales y barrios obreros en América Latina en el siglo XX. Revista de Urbanismo, (36), 3-16. http://dx.doi. org/10.5354/0717-5051.2017.45198 
Vergara, J. (2017). Verticalización. La edificación en altura en la Región Metropolitana de Santiago (1990-2014). INVI, 32 (90), 9-49. https://dx.doi.org/10.4067/S071883582017000200009

Vergara, J. y Asenjo, D. (2019). Arquitectura y densidad. Revista de Arquitectura, 24(36), 32-39. https://doi. org/10.5354/0719-5427.2019.53771

Subercaseaux, R. (1920) Congreso de Habitaciones de Londres. Revista de la Habitación, 1 (1), 8-15.

Winfield, F. y Marti, D. (2013). Urbanismo y modernidad. La influencia de las ciudades jardín en México: 19211930. Arquitecturas del Sur, 44(31), 34-47. http:// revistas.ubiobio.cl/index.php/AS/article/view/755 